\title{
OSAHS
}

\section{Surgical treatment of epiglottis collapse in obstructive sleep apnoea syndrome: epiglottis stiffening operation}

\author{
Trattamento chirurgico dell'instabilità epiglottica nella sindrome delle apnee \\ ostruttive del sonno: "epiglottis stiffening operation" (intervento di stabilizzazione \\ dell'epiglottide) \\ F. SALAMANCA, F. LEONE, A. BIANCHI, R.G.S. BELLOTTO, F. COSTANTINI, P. SALVATORI \\ Unit of Otorhinolaryngology, Head and Neck Surgery, Humanitas San Pio X, Milan, Italy
}

\begin{abstract}
SUMMARY
The epiglottis is an important structure that was largely ignored in early research on obstructive sleep apnoea/hypopnoea syndrome (OSAHS). Primary epiglottis collapse (EC) in patients with OSAHS is difficult to treat with conservative therapies, such as oral appliances and CPAP. Therefore, surgical treatment may represent a good option when dealing with EC, although up to now no standardised surgical procedures have been described. Herein, we describe a new surgical procedure that we called "epiglottis stiffening operation" (ESO); the technique is safe, devoid of complications, easy to perform and is effective in treatment of primary EC, which presents as a single or coexistent site of upper airway obstruction without altering fundamental functions of the epiglottis.
\end{abstract}

KEY WORDS: Epiglottis collapse $\bullet$ Epiglottis surgery $\bullet$ Surgery $\bullet$ Obstructive sleep apnoea $\bullet$ Snoring

\section{RIASSUNTO}

L'instabilità epiglottica, o collasso epiglottico primario, è una condizione spesso sottovalutata nell'ambito della terapia delle apnee ostruttive in sonno e costituisce una problematica difficile da trattare. Le terapie conservative come la CPAP o l'utilizzo di Oral Appliance possono non essere sufficienti a risolvere tale problema o in alcuni casi addirittura peggiorare la condizione. In questi casi un trattamento chirurgico potrebbe rappresentare una buona opzione terapeutica sebbene ad oggi non siano state standardizzate delle procedure volte a correggere il collasso epiglottico. L'obiettivo di questo lavoro è di illustrare una nuova tecnica chirurgica denominata "epiglottis stiffening operation" (ESO), ovvero "intervento di stabilizzazione dell'epiglottide”; tale procedura si è rivelata sicura, priva di complicanze, facile da eseguire e soprattutto efficace nel risolvere il collasso epiglottico primario senza alterare le fisiologiche funzioni dell'epiglottide. .

PAROLE CHIAVE: Collasso epiglottico $\bullet$ Epiglottoplastica $\bullet$ Roncochirurgia $\bullet$ Roncopatia $\bullet$ Russamento

\section{Introduction}

The identification of upper respiratory tract obstruction site(s) in patients with obstructive sleep apnoea/hypopnoea syndrome (OSAHS) is important to select the best therapeutic strategy. Nowadays, among different diagnostic tools, drug-induced sleep endoscopy (DISE), although not ideal, plays a key role in the decision making process ${ }^{1}$. The introduction of routine use of DISE studies in OSAHS patients demonstrated that upper airway (UA) obstruction results from the collapse of one or more pharyngeal and/or laryngeal structures ${ }^{2-4}$.

Laryngeal involvement consists, in the large majority of patients, in collapse of the epiglottis; this may be primary (in which case it is described as "floppy epiglottis") or secondary, when a bulky tongue base pushes the epiglottis backwards. Epiglottic collapse (EC) is difficult to treat with conservative therapies, such as oral appliances ${ }^{56}$ and $\mathrm{CPAP}^{7}$. Therefore, its identification has important implications for surgical treatment.

Herein, we describe a new surgical procedure that we called "epiglottis stiffening operation" (ESO); the technique is safe, devoid of complications, easy to perform and very effective in treatment of primary EC, which presents as a single or coexistent site of UA obstruction without altering the fundamental functions of the epiglottis.

\section{Methods}

A retrospective review of all patients affected by OSAHS 
who were treated between March 2014 and February 2019 at the Department of Otorhinolaryngology of the Humanitas San Pio X, a referral centre for the management of sleep-related breathing disorders, was carried out.

Inclusion criteria were: patients who underwent an ESO within multimodal management of a sleep-related breathing disorder; diagnosis of primary EC after a DISE (Fig. 1A); conservative therapy refused, not indicated or insufficient; available clinical and follow-up data.

The preoperative diagnostic work-up included complete physical examination, endoscopic evaluation, polysomnographic study (PSG) and DISE. Treatment was planned taking into account clinical features and individual patient preferences.

Surgery was performed in all cases by skilled surgeons. After surgery, on the $1^{\text {st }}$ post-operative day, a verbal $\mathrm{Nu}-$ merical Rating Scale 11 (vNRS-11) and Eating Assessment Tool 10 (italian version) (I-EAT-10) ${ }^{8}$ were administered before patients were discharged. Patients were followed for at least 3 months postoperatively according to our protocol that includes endoscopic evaluation on the $7^{\text {th }}$ and $30^{\text {th }}$ postoperative days and PSG at about 3 months. Epidemiological and clinical data, surgical reports, outcomes, complications, and follow-up information were reviewed.

From a technical viewpoint, body mass index $(\mathrm{BMI})>35$ and other factors (e.g. presence of trismus, mandibular prognathism, etc.) making laryngeal exposure difficult ${ }^{9}$, should be considered as restrictions precluding the use of our technique. This study was performed in accordance with policies approved by the local ethics Committee.

\section{Surgical technique}

Exposition of the epiglottis in direct micro-laryngoscopy is performed as usual. The lower half of the lingual side of the epiglottis is cauterised in the area be- tween the lateral glosso-epiglottic folds (including the median glosso-epiglottic fold) using suction cautery avoiding reaching the free margin of the epiglottis itself (Fig. 1B). In this phase, it is important to reach the perichondrium in order to induce stiffening and scar retraction of tissues as a result of healing by second intention (Fig. 1C).

\section{Results}

From March 2014 to February 2019, we performed 759 DISE procedures identifying a total of $87(11 \%)$ patients with primary EC. In 22 cases, we concluded that the use of CPAP ventilation was indicated, and that the treatment was satisfactory; 51 patients underwent ESO within multilevel surgery; a total of 14 patients, who underwent ESO. exclusively, fulfilled the inclusion criteria of the present study and form the population of our retrospective survey. Demographic data of patients are summarised in Table I.

A strong male predominance was found since only 1 patient was a woman $(7.2 \%)$, while 13 were men $(92.8 \%)$; the mean age was 55.9 years (range 47-76). Mean BMI was $25.6 \mathrm{~kg} / \mathrm{m}^{2}$ (range 22.1-34). Four (28.57\%) patients were affected by simple snoring, $5(35.71 \%)$ by mild OSAHS, $2(14.28 \%)$ by moderate OSAHS and 3 $(21.42 \%)$ by severe OSAHS. The post-operative course of all patients was uneventful and substantially without pain (vNRS-11 range from 0 to 3 ) with discharge in the $1^{\text {st }}$ postoperative day. Moreover, no patient had dysphagia, aspiration (I-EAT 10 range from 0 to 2 ) or dysphonia. Follow-up ranged between 3 and 15 months (mean, 7.21 months) and most patients were lost after 6 months. Postoperative naso-laryngoscopy on $7^{\text {th }}$ and $30^{\text {th }}$ postoperative day showed good results in terms of retraction of the epiglottis in all patients. Additionally, five patients

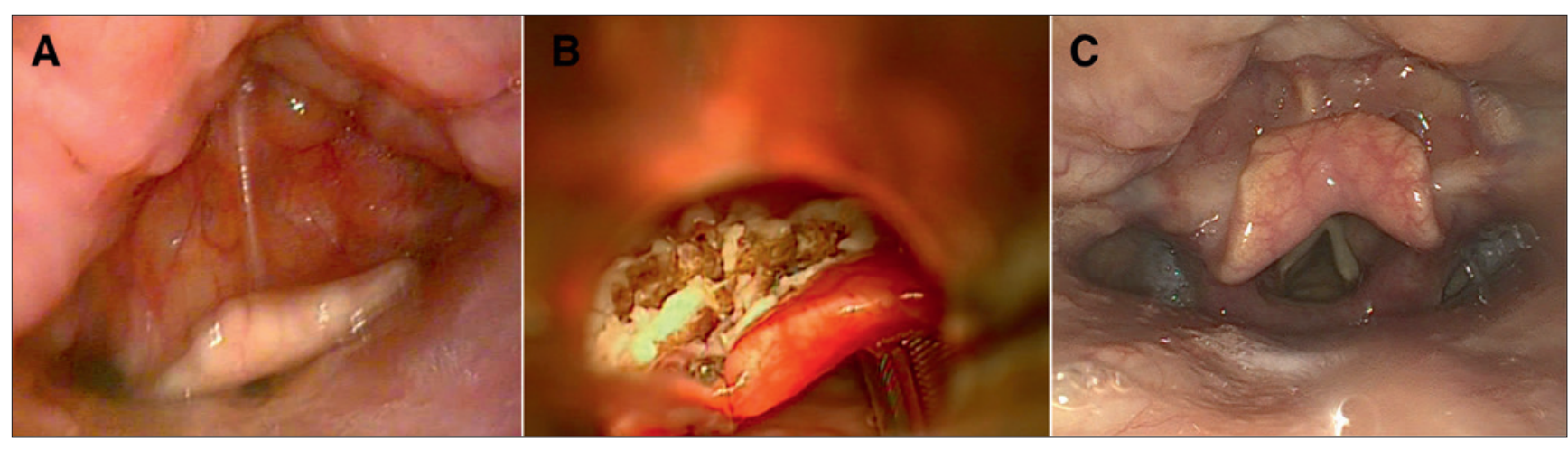

Fig. 1. A) DISE evidence of primary epiglottis collapse. B) Aspect of epiglottis at the end of epiglottis stiffening operation. C) Epiglottis retraction 1 month after the surgical procedure. 
underwent postoperative DISE with no evidence of epiglottic collapse.

\section{Discussion}

The epiglottis is an important anatomical structure that was largely ignored and/or underestimated in the early research on obstructive breathing disorders ${ }^{10}$. Recent studies, however, have shown that it plays an important role, either on its own or in combination with other pharyngeal structures ${ }^{11}{ }^{12}$. Nowadays, thanks to the introduction of DISE, it is possible to show that the prevalence of EC in determining the airway obstruction is actually much higher and ranges from $10 \%$ to $40 \%$ of patients ${ }^{12}{ }^{13}$. Our survey confirms these findings with a prevalence of primary EC of $11 \%$ (87/759).

Primary collapse of the epiglottis represents a challenging situation because CPAP may sometimes aggravate airway obstruction by further pushing the epiglottis down into the laryngeal aditus ${ }^{714}$. This was the case in 1 patient (see Table I) of our sample, who presented with a poor response to CPAP as a result of an occult EC. In such cases, ESO improved the effectiveness of CPAP.

Furthermore, epiglottic collapse can be revealed by performing a mandibular pull-up during DISE, making it difficult to exclusively treat with an oral appliance ${ }^{515}$. Of note, in our series, 7 patients affected by OSAHS and
2 patients affected by simple snoring (Table I) manifested EC at DISE mandibular pull-up. In these situations, ESO became necessary for subsequent treatment with a mandibular advancement device (MAD). For all these reasons, surgical treatment may represent a good option when dealing with EC though up to now no standardised surgical procedures have been described.

It is important to remember that the epiglottis plays a role in preventing inhalation thanks to its sensitive receptors (distributed on the laryngeal surface, ariepiglottic folds, arytenoids and posterior commissure) that stimulate the so-called "glottis closure reflex" ${ }^{15}$. This is the reason why in 2014 we stopped performing "partial epiglottectomy" 16 for treatment of primary epiglottis collapse, developing the surgical procedure reported herein.

Thinking about a new procedure to solve the problem of EC, we thought of the CAPSO (cautery assisted palate stiffening operation) described by Pang ${ }^{17}$, which consisted in the removal of an area of palatal mucosa with an electric scalpel inducing scar retraction without sutures to reduce snoring/palatal prolapse by stiffening the soft palate. In the same way, we applied this principle at the level of the lingual surface of the epiglottis, calling our procedure ESO.

Some tips and tricks must be taken into account when

Table I. Preoperative data and outcomes.

\begin{tabular}{|c|c|c|c|c|c|c|c|c|c|c|c|c|c|}
\hline \multirow[b]{2}{*}{$\#$} & \multicolumn{5}{|c|}{ Preoperative data } & \multirow{2}{*}{$\begin{array}{l}\text { Surgical } \\
\text { procedure }\end{array}$} & \multicolumn{6}{|c|}{ Postoperative evidences } & \multirow{2}{*}{$\begin{array}{l}\text { Follow up } \\
\text { (months) }\end{array}$} \\
\hline & Age & Sex & BMI & ESS & AHI & & $\mathrm{OA}$ & vNRS-11 & I-EAT-10 & Examination & AHI & ESS & \\
\hline 1 & 49 & M & 26.6 & 1 & 8.9 & ESO & Y & 1 & 1 & DISE & 2.3 & 1 & 15 \\
\hline 2 & 47 & M & 27.3 & 5 & 18 & ESO & Y & 2 & 0 & DISE & 4.2 & 4 & 13 \\
\hline 3 & 49 & M & 24.4 & 3 & 0.1 & ESO & Y & 1 & 0 & DISE & Snoring solved & 3 & 6 \\
\hline 4 & 55 & M & 21.7 & 3 & 7.7 & ESO & Y & 0 & 0 & FNLS & 3.7 & 3 & 6 \\
\hline 5 & 55 & $\mathrm{~F}$ & 27.9 & 3 & 2.9 & ESO & $\mathrm{N}$ & 1 & 1 & FNLS & Snoring solved & 3 & 6 \\
\hline 6 & 62 & M & 24.8 & 9 & 57.6 & ESO & $Y$ & 3 & 2 & FNLS & 6.8 & 5 & 9 \\
\hline 7 & 71 & M & 22.1 & 2 & $\begin{array}{c}45 \\
(12.3 \\
\text { with CPAP) }\end{array}$ & ESO & $\mathrm{N}$ & 2 & 1 & FNLS & 0.2 with CPAP & 2 & 11 \\
\hline 8 & 76 & M & 23.9 & 8 & 9.4 & ESO & $N$ & 1 & 0 & FNLS & 3.4 & 5 & 7 \\
\hline 9 & 49 & M & 23.4 & 4 & 9.3 & ESO & $N$ & 1 & 0 & FNLS & 0.2 & 3 & 6 \\
\hline 10 & 62 & M & 24.6 & 4 & 3.7 & ESO & $\mathrm{N}$ & 0 & 0 & FNLS & Snoring solved & 4 & 6 \\
\hline 11 & 58 & M & 26.6 & 6 & 24 & ESO & Y & 1 & 0 & DISE & 3.7 & 4 & 4 \\
\hline 12 & 70 & M & 25.2 & 5 & 4.1 & ESO & Y & 2 & 1 & FNLS & Snoring solved & 5 & 6 \\
\hline 13 & 60 & $M$ & 25.6 & 5 & 14.9 & ESO & $Y$ & 3 & 2 & DISE & 1.9 & 4 & 3 \\
\hline 14 & 56 & M & 34 & 7 & 56.1 & ESO & Y & 1 & 0 & FNLS & 4.3 & 7 & 3 \\
\hline
\end{tabular}

M: male; F: female; BMI: Body Mass Index; ESS: Epworth Sleepiness Scale; AHI: Apnea Hypopnea Index; ESO: Epiglottis Stiffening Operation; OA: Oral Appliance; CPAP: Continuous Positive Airway Pressure; vNRS-11: verbal Numerical Rating Scale 11; I-EAT-10: Eating Assessment Tool 10 (Italian version); FNLS: Fibre-optic Nasolaryngoscopy; DISE: Drug Induced Sleep Endoscopy. 
performing ESO: a) scarification is made using a suction cautery to remove excess of lax tissues; b) it is important to reach the perichondrium of the lingual side of epiglottis, especially on the midline, in order to induce effective stiffening in the direction of median thyroepiglottic ligament; c) it is necessary to leave a rim of healthy tissue along the free border of the epiglottis to preserve sensitive receptors, allowing the activation of reflexes.

Since its advent as a tool for the treatment of OSAHS, the scope of surgery has evolved to address multiple areas of obstruction simultaneously ${ }^{18} 19$ and treatment of epiglottis collapse is generally bundled into procedures that target multiple areas of obstruction, explaining why we currently lack sufficient evidence to support any treatment that may specifically address this issue. This is the reason why, in order to validate our technique without any other interferences, we selected only patients who exclusively underwent ESO. Moreover, with the aim of validating our technique, in a small sample of patients we performed a postoperative DISE that confirmed in all cases the good outcomes of surgery.

To date, different surgical approaches ${ }^{15} 1620$ have been described with the aim of treating this peculiar region, but some of these are technically complex and associated with complications, such as bleeding, oedema, persistent dysphagia, dysgeusia, etc. ${ }^{20}$.

In the future, clear understanding of such complex condition and the key factors that play a role into different UA obstruction patterns might help in identifying better surgical indications and targeted surgical strategies.

\section{Conclusions}

In conclusion, the ESO is aimed to resolve just one characteristic of our OSAHS patients, namely primary epiglottis collapse without taking the burden to cure OSAHS. Our experience allows us to affirm that it is a safe procedure, devoid of complications, easy to perform and effective in treating EC that presents as a single or coexistent site of UA obstruction without altering the fundamental functions of the epiglottis. Healing time after this surgery is shorter than that after partial epiglottectomy; moreover, ESO can be associated with other techniques in a multimodal multilevel surgical treatment. Larger case series with longer follow-up are needed to confirm these results.

\section{Conflict of interest statement}

None declared.

\section{References}

1 Delakorda M, Ovsenik N. Epiglottis shape as a predictor of obstruction level in patients with sleep apnea. Sleep Breath 2018;149:1-7. https://doi.org/10.1007/s11325-018-1763-y

2 Azarbarzin A, Marques M, Sands SA, et al. Predicting epiglottic collapse in patients with obstructive sleep apnoea. Eur Respir J 2017;50. https://doi.org/10.1183/13993003.00345-2017

3 Salamanca F, Costantini F, Bianchi A, et al. Identification of obstructive sites and patterns in obstructive sleep apnoea syndrome by sleep endoscopy in 614 patients. Acta Otorhinolaryngol Ital 2013;33:261-6

4 Campanini A, Canzi P, De Vito A, et al. Awake versus sleep endoscopy: personal experience in 250 OSAHS patients. Acta Otorhinolaryngol Ital 2010;30:73-7

5 Kent DT, Rogers R, Soose RJ. Drug-induced sedation endoscopy in the evaluation of OSA patients with incomplete oral appliance therapy response. Otolaryngol Head Neck Surg 2015;153:302-7. https://doi.org/10.1177/0194599815586978

6 Giarda M, Brucoli M, Arcuri F, et al. Efficacy and safety of maxillomandibular advancement in treatment of obstructive sleep apnoea syndrome. Acta Otorhinolaryngol Ital 2013;33:43-6

7 Verse T, Pirsig W. Age-related changes in the epiglottis causing failure of nasal continuous positive airway pressure therapy. J Laryngol Otol 1999;113:1022-5. https://doi.org/10.1017/ S0022215100145888

8 Schindler A, Mozzanica F, Monzani A, et al. Reliability and validity of the Italian Eating Assessment Tool. Ann Otol Rhinol Laryngol 2013;122:717-24. https://doi. org/10.1177/000348941312201109

9 Incandela F, Paderno A, Missale F, et al. Glottic exposure for transoral laser microsurgery: proposal of a mini-version of the laryngoscore. Laryngoscope 2018;24:135-7. https://doi.org/10.1002/ lary. 27525

10 Catalfumo FJ, Golz A, Westerman ST, et al. The epiglottis and obstructive sleep apnoea syndrome. J Laryngol Otol 1998;112:9403. https://doi.org/10.1017/S0022215100142136

11 Kwon OE, Jung SY, Al-Dilaijan K, et al. Is epiglottis surgery necessary for obstructive sleep apnea patients with epiglottis obstruction? Laryngoscope 2019;115:538-6. https://doi. org/10.1002/lary.27808

12 Torre C, Camacho M, Liu SY-C, et al. Epiglottis collapse in adult obstructive sleep apnea: a systematic review. Laryngoscope 2015;126:515-23. https://doi.org/10.1002/lary.25589

13 Cavaliere M, Russo F, Iemma M. Awake versus drug-induced sleep endoscopy: Evaluation of airway obstruction in obstructive sleep apnea/hypopnoea syndrome. Laryngoscope 2013;123:23158. https://doi.org/10.1002/lary.23881

14 Dedhia RC, Rosen CA, Soose RJ. What is the role of the larynx in adult obstructive sleep apnea? Laryngoscope 2013;124:1029-34. https://doi.org/10.1002/lary.24494

15 Roustan V, Barbieri M, Incandela F, et al. Transoral glossoepiglottopexy in the treatment of adult obstructive sleep apnoea: a surgical approach. Acta Otorhinolaryngol Ital 2018;38:38-44. https://doi.org/10.14639/0392-100X-1857

16 Oluwasanmi AF, Mal RK. Diathermy epiglottectomy: endoscopic technique. J Laryngol Otol 2006;115:289-92. https://doi. org/10.1258/0022215011907479

17 Pang KP, Terris DJ. Modified cautery-assisted palatal stiffening operation: new method for treating snoring and mild obstruc- 
tive sleep apnea. Otolaryngol Head Neck Surg 2016;136:823-6. https://doi.org/10.1016/j.otohns.2006.11.014

18 Lin H-C, Friedman M, Chang H-W, et al. The efficacy of multilevel surgery of the upper airway in adults with obstructive sleep apnea/hypopnea syndrome. Laryngoscope 2008;118:902-8. https:// doi.org/10.1097/MLG.0b013e31816422ea

19 Montevecchi F, Meccariello G, Firinu E, et al. Prospective multi- centre study on barbed reposition pharyngoplasty standing alone or as a part of multilevel surgery for sleep apnoea. Clin Otolaryngol 2017;43:483-8. https://doi.org/10.1111/coa.13001

20 Bourolias C, Hajiioannou J, Sobol E, et al. Epiglottis reshaping using CO2 laser: A minimally invasive technique and its potent applications. Head Face Med 2008;4:539-4. https://doi. org/10.1186/1746-160X-4-15

Received: May 9, 2019 - Accepted: August 18, 2019

How to cite this article: Salamanca F, Leone F, Bianchi A, et al. Surgical treatment of epiglottis collapse in obstructive sleep apnoea syndrome: epiglottis stiffening operation. Acta Otorhinolaryngol Ital 2019;39:404-408. https://doi.org/10.14639/0392-100X-N0287

Address for correspondence: Federico Leone, Unit of Otorhinolaryngology, Head and Neck Surgery, Humanitas, San Pio X Clinic, via Francesco Nava 31, 20159 Milan, Italy. E-mail federico.leone@email.com 